The Psychological Record, 2011, 61, 127-140

\title{
EXAMINING ANTECEDENT CONTROL OVER EMERGENT MANDS AND TACTS IN YOUNG CHILDREN
}

\author{
Claire E. Egan and Dermot Barnes-Holmes \\ National University of Ireland, Maynooth
}

\begin{abstract}
This study examined the functional independence of mand and tact operants in normally developing children and evaluated the role of $S^{D} S$ in demonstrating emergent responding. In Experiment 1, 4 children aged 4 to 5 years, were trained to mand or tact using left/right relations, then were tested for the emergence of the untaught tact/ mand operant. None of the participants demonstrated an emergence of the untaught operant under standard antecedent conditions. However, all of the participants demonstrated an emergence of the untaught operant when the $S^{D} S$ were modified. Experiment 2 replicated the work in Experiment 1, using 8 participants. The conditions were reversed according to $A B A B$ reversal design methodology and counterbalanced across participants. The findings demonstrated the important role of antecedent variables in emergent responding.
\end{abstract}

Key words: mand, tact, functional independence

In 1957, B. F. Skinner published the first behavior analytic account of human language in his book Verbal Behavior. In that account, Skinner outlined several classes of verbal operants, each defined by its unique controlling variables. These provided the framework necessary for a functional analysis of human language. The distinction between two of these classes, the mand and the tact, has been the subject of discussion and empirical investigation (Lamarre \& Holland, 1985; Murphy \& Barnes-Holmes, 2009; Petursdottir, Carr, \& Michael, 2005; Schlinger, 2008; Sigafoos, Reichle, Doss, Hall, \& Pettitt, 1990; Sundberg, San Juan, Dawdy, \& Arguelles, 1990; Wallace, Iwata, \& Hanley, 2006).

Mands are controlled by relevant establishing operations and specific reinforcers, whereas tacts are controlled by a discriminative stimulus $\left(S^{D}\right)$ and generalized reinforcement. The following scenario illustrates a mand. Following a period of deprivation from water, a child says to a

Claire E. Egan is now at The Hong Kong Institute for Education.

These experiments were completed as part of the doctoral work submitted by Claire E. Egan to the Department of Psychology at NUI, Maynooth. We would like to thank Dr. Chris Ninness for his invaluable comments on an earlier draft of this manuscript.

Correspondence concerning the study should be addressed to Claire E. Egan, Department of Educational Psychology, Counselling, and Learning Needs, Hong Kong Institute of Education, 10 Lo Ping Road, Tai Po, NT, Hong Kong-SAR (e-mail: claire@ied.edu.hk). 
parent, "Water" and is given water. In this example, deprivation of liquids has occurred. As a result, the child specifies the reinforcer (water) and the parent mediates the reinforcement by providing water. The same response form "water" occurring as a tact is illustrated in the following example, A child sees running water and says "water" then receives praise from a parent. The child responds to an $S^{\mathrm{D}}$ (water), and the parent provides generalized reinforcement (praise). Skinner proposed that the distinct variables controlling mands and tacts made these two verbal operants functionally independent. The same response form thus could be categorized as a tact or a mand, depending on the controlling variables present in a given context. Furthermore, the acquisition of a particular response form with the controlling variables of a tact would not necessarily result in the emergence of that response form with the controlling variables of a mand.

Lamarre and Holland (1985) published the first experimental investigation of the functional independence of mand and tact operants in humans. It was a seminal study because it was the first empirical study supporting Skinner's (1957) theoretical model of functionally distinct mand and tact operants. These authors studied nine normally developing children, aged 3 to 5 years. The participants were assigned to mand or tact training conditions and were taught to respond to left/right relations, using multiple object pairs. Of the nine participants, four received training to respond under mand conditions and the remaining five were trained in the tact conditions. Following this training, the participants were tested for the emergence of the untaught operant, but none of the children demonstrated this emergent performance. Then each of the subjects was successfully trained on the previously tested operant, so all subjects demonstrated both tact and mand operants. Lamarre and Holland then trained each participant in the reverse relations using the initially trained operant. That is, participants who were first trained on mands were reverse trained on this operant, and participants first trained on tacts were reverse trained on this operant. Following this training, six of the participants continued to demonstrate an absence of transfer across the conditions. The remaining three participants demonstrated an emergence of the untaught operant following reverse training. Lamarre and Holland concluded that their results offered direct evidence to support Skinner's theory of functionally distinct verbal operants. Specifically, training a response form under the controlling variables of the mand (or tact) did not result in the emergence of that same response form under the controlling variables of the tact (or mand).

Despite the influential findings of the study, it did not generate any direct replications following its publication in 1985. There have been subsequent studies that have sought to examine the independence of function between mands and tacts (Hall \& Sundberg, 1987; Nuzzolo-Gomez \& Greer, 2004; Petursdottir et al., 2005; Sigafoos et al., 1990; Sundberg et al., 1990; Twyman, 1996; Wallace et al., 2006). However, results have shown inconsistent evidence for functionally distinct mand/tact operants. One explanation for this inconsistency may be the differences across the studies in procedural and participant variables. Specifically, all of the studies published subsequent to Lamarre and Holland employed experimental procedures that deviated from the original work. Furthermore, only one study examined participants who were normally developing and matched in age (Petursdottir et al., 2005). Interestingly, however, even this study did 
not replicate the findings published by Lamarre and Holland, despite the similarities in the participant variables.

Although Skinner (1957) proposed a functional independence between mand and tact operants based on the unique antecedent and consequential controlling variables, he acknowledged that transfer of behavioral control across mands and tacts could be observed in the mature speaker. He suggested that a person with a history of reinforcement for mands using specific frames (i.e., "I want") could demonstrate an emergence of newly trained tacts within the mand frame. Sigafoos et al. (1990) supported this idea empirically by demonstrating a transfer from tact to mand variables under the control of mand frames established through training. These findings showed that functional independence was not observed once an $\mathrm{S}^{\mathrm{D}}$ was presented to cue the participants to the change from tact to mand contingencies.

Skinner (1957) described a second circumstance in which mand/tact emergence may be observed following training. He reasoned that transfer across mand and tact operants might occur in cases where common sources control these operants. He described these as instances of "impure" verbal operants, due to the mixture of mand/tact controlling relations. Previous research has examined the functional independence of mands and tacts classified as impure verbal operants (Lamarre \& Holland, 1985; Petursdottir et al., 2005; Twyman, 1996) and pure verbal operants (Nuzzolo-Gomez \& Greer, 2004; Partington et al., 1994; Twyman, 1996; Wallace et al., 2006). No consistent differences in mand/tact emergence are apparent when comparing the results of studies testing "impure" controlling relations with those testing "pure" controlling relations. However, more systematic examination of the role of specific $S^{\mathrm{D}} \mathrm{s}$ in testing for mand/tact emergence is necessary.

A recent study by Wallace and colleagues (2006) compared the emergence of mands following tact training with high- and low-preference items for three adults with mental retardation. They identified high- and low-preference items using preference assessment and then trained the participants to tact each item. Following tact training, the emergence of the response was tested under mand conditions. Results showed that the untrained mand response initially emerged for both high- and lowpreference items but was maintained only when the consequence of the mand was a high-preference reinforcer. Therefore, the motivational operations established by differentially reinforcing mand responses during mand tests diminished the transfer from tacts to mands, despite the initial emergence observed. Although responses to the mand test conditions were brought under motivational control rapidly, these findings indicated that $\mathrm{S}^{\mathrm{D}} \mathrm{S}$ controlled initial mand emergence.

Most recently, a preliminary study by the current authors (Egan \& Barnes-Holmes, 2009) presented further evidence that antecedent variables can affect the emergence of untaught mand/tact responses following training. Four male students with autism, aged 5 to 7 years, were trained to respond with adjective sets in mand conditions. Then the participants were tested to evaluate the emergence of the untrained tact operant. In other words, participants who were trained to mand using adjectives were tested for emergent tacts using adjectives following training. Results showed that training adjective sets as mands did not result in the emergence of those adjective sets as tacts. However, when the experimenters modified the $S^{\mathrm{D}} \mathrm{s}$ 
during posttraining probes, the participants did demonstrate an emergence of the untaught response.

In summary, outcomes of several studies in this area have supported a functional distinction between tacting and manding through the nonemergence of the untaught function (Lamarre \& Holland, 1985; NuzzoloGomez \& Greer, 2005; Twyman, 1996). However, challenges to this view suggest that further investigation of the role of antecedent variables is warranted (Egan \& Barnes-Holmes, 2009; Partington et al., 1994; Sundberg et al., 2000; Wallace et al., 2006).

The aim of the present studies was to investigate further the functional independence of mand/tact operants by replicating Lamarre and Holland's (1985) original work more closely than has been done hitherto in the literature. In addition, the role of specific antecedents in exerting discriminative control over mand/tact emergence was evaluated by including standard and modified antecedent conditions.

\section{Experiment 1}

We assessed whether functional independence could be established using procedures outlined by Lamarre and Holland (1985). One procedural modification was incorporated for Experiment 1; specifically, we did not train or test for "left/right" responses under the "reversed" conditions described in the introduction.

\section{Method}

Participants, Settings, and Materials. The participants were four normally developing children, aged 4 to 5 years, who attended a Montessori preschool. Participants were selected for the study if they demonstrated the ability to point to and vocally tact the objects used in the study, and if they failed to demonstrate left/right relations under mand and tact conditions, following listener training (described under Pre-experimental Probes). Experimental sessions were conducted in a small room attached to the Montessori classroom and were 25 minutes in duration; each participant was exposed to a maximum of one session per day. A plastic horse and a wooden block were the materials used during all probe and training sessions. Before the start of each trial, these items were placed on the table in random order in front of the participant.

Dependent Variable. The dependent variable was the number of correct responses to probes for untaught mands and tacts for left and right relations.

Independent Variables. Two categories of independent variables were presented in the current study: type of experimental training and type of postexperimental probe.

Type of Experimental Training. Each participant was trained to respond accurately under either mand or tact conditions (see Experimental Training below).

Type of Postexperimental Probe. Following experimental training (mand or tact), participants were tested for the emergence of the untrained operants (tact or mand) under standard and modified antecedent conditions (see Postexperimental Probes below). 
Procedure. The experimental sequence involved mand assessment training, pre-experimental probes, experimental training, and postexperimental probes.

Mand Assessment Training. Mand assessment trials were implemented during mand training and probe trials (described below). The purpose of the mand assessment trials was to verify that participants were accurately discriminating left/right positions. Participants were taught to evaluate the accuracy of the experimenter's placement of the item in the location specified by the participant (i.e., "on the left" or "on the right").

To begin, participants were taught to evaluate the accuracy of the experimenter's responses to participant instructions during an identitymatching task. The participant was taught to present instructional trials to the experimenter. Response prompts, such as modeling and verbal instructions, were used to teach the participant to present a lowercase letter as a sample stimulus, and then instruct the experimenter to "Match" and then record the experimenter's response. Following each response, either correct or incorrect, the experimenter asked, "Did I get it right or wrong?" The participant was taught to record a plus sign when the experimenter got it right and a minus sign when the experimenter got it wrong (e.g., matching $c$ with $c$ and matching $c$ with $n$, respectively). The experimenter deliberately matched the incorrect letter once out of every four trials, on average, to ensure that each participant could discriminate the experimenter's correct from incorrect responding and was willing and able to report this to the experimenter. Training continued until the participant scored the experimenter's responding accurately on $4 / 4$ consecutive trials.

Once participants were taught to reliably evaluate the experimenter's performance, we conducted screening procedures to determine whether participants could demonstrate left/right relations under standard mand, standard tact, and listener probe conditions. During all subsequent mand probe conditions, the participant recorded the experimenter's responses as being either correct or incorrect. The participant used a paper and pencil to record a "+" when the experimenter responded correctly and a "-" when the experimenter responded incorrectly. The experimenter deliberately placed the item in the wrong location once out of every four trials, on average. Following placement of the item for each trial, the experimenter asked, "Did I get the answer right or wrong?" Correct responses were defined as the participant's correctly recording the experimenter's response to the participant's mand (i.e., left or right); incorrect responses were defined as those recorded incorrectly or those that did not occur within $5 \mathrm{~s}$ following the experimenter's question. The participants received no verbal feedback during mand probe conditions.

Pre-Experimental Probes-Standard Mand Probes. The experimenter placed one item on the table on either the left- or right-hand side and held the other in front of the participant. The participant was asked, "Where do you want me to put the [item]?" Across trials, the experimenter rotated placement of the items on either the left or right in quasirandom order. There were eight probe trials presented in total (see Table 1). Correct responses were vocal mands specifying the available location (left or right); incorrect responses were those that did not include the correct location or did not occur within $5 \mathrm{~s}$. During mand probe conditions, the participant recorded the experimenter's responses as being either correct or incorrect. If the participant did not accurately record the experimenter's response, the mand probe trial was recorded as incorrect. 
Table 1

Operant Components for Standard Mand Probe Conditions

\begin{tabular}{cccc}
\hline & Antecedent & Standard response & Consequence \\
\hline Block on left of table & "Where do you want me to put the & "On the right" & None \\
hlock on right of table & "Where do you want me to put the & "On the left" & None \\
horse on left of table & "Where do you want me to put the & "On the right" & Nock?" \\
Horse on right of table & "Where do you want me to put the & "On the left" & Nock?" \\
\hline
\end{tabular}

Standard Tact Probes. The experimenter placed each item on the table in front of the participant and asked, "Where is the [item]?" Correct responses were tacts that included the correct location (left or right); incorrect responses were tacts that did not include the correct location or did not occur within $5 \mathrm{~s}$. Following the participant's response, both items were removed from the table and no other consequence was delivered. Eight probe trials were presented in total (see Table 2).

Table 2

Operant Components for Standard Tact Probe Conditions

\begin{tabular}{cccc}
\hline & Antecedent & Standard response & Consequence \\
\hline Block on right of horse & "Where is the block?" & "On the right" & None \\
Block on left of horse & "Where is the block?" & "On the left" & None \\
Horse on right of block & "Where is the horse?" & "On the right" & None \\
Horse on left of block & "Where is the horse?" & "On the left" & None \\
\hline
\end{tabular}

Listener Training. The experimenter placed one item on the table in front of the participant, held up the other item, and instructed, "Put the [item] on the [left/right]." The experimenter rotated the order and location of items at random. Correct and incorrect responses were defined as the participant's placing the item in the correct or incorrect location, respectively. In addition, a response was recorded as incorrect if it did not occur within $5 \mathrm{~s}$ of the experimenter's instruction. The experimenter used praise and tokens to reinforce correct responding. For incorrect responses, the experimenter repeated the instruction and modeled the response.

Following listener training, standard mand and tact probes were repeated to assess the impact of listener training on emergent left/right responding. None of the participants passed the mand/tact probes following listener training.

Experimental Training. Following pre-experimental probes, participants were trained to respond accurately under either mand or tact conditions. Participants 3 and 4 were trained in mand conditions, and Participants 1 and 2 were trained in tact conditions.

Mand Training. During mand training, the participants were taught to mand using left/right relations (Lamarre \& Holland, 1985). The participants were trained to respond to mand conditions by vocally specifying placement of the item in a target location (i.e., left or right). First, the experimenter 
placed one item on the table, rotating left and right positions at random across trials, and held the other item up in front of the participant. Then the experimenter asked, "Where do you want me to put the block/horse?" If the participant manded either "left" or "right," the experimenter placed the item in the corresponding available location. If the participant emitted any other mand, such as "on your head," the experimenter presented a vocal model by saying "on the left" or "on the right." The experimenter then put away the item and began a new trial. Training for mands continued until participants met the predetermined mastery criterion of $8 / 8$ consecutive correct responses for each relation.

Tact Training. During tact training, the participants were taught to specify the location of the items as being "on the left" or "on the right" using a vocal response. The experimenter placed both items on the table, rotating left/right positions at random, and asked, "Where is the horse/block?" A response was recorded as correct if the participant accurately identified the available location (i.e., left/right), and the experimenter delivered praise and tokens. Tokens were exchanged for preferred items or activities following every four correct responses, on average. A response was recorded as incorrect if it did not specify the correct location, or if it did not occur within $5 \mathrm{~s}$ of the experimenter's instruction. In response to errors, the experimenter repeated the question and modeled the correct response for the participant. The participant was required to repeat the response before beginning a new trial. Training continued until 8/8 consecutive correct responses occurred.

Postexperimental Probes. Following training, two probes were conducted: a standard mand/tact probe (described above) and a modified mand/tact probe (see Table 3). Participants who were trained under mand conditions were probed under standard and modified tact conditions. Participants who were trained under tact conditions were probed under standard and modified mand conditions.

Table 3

Operant Components for Modified Mand and Tact Probe Conditions

\begin{tabular}{cccc}
\hline Operant & \multicolumn{1}{c}{ Antecedent } & Response & Consequence \\
\hline Mand & $\begin{array}{l}\text { Experimenter asks, "Where do } \\
\text { you want me to put the [item]? } \\
\text { Which side?" and points to left } \\
\text { and right. }\end{array}$ & "On the right/left" & None \\
& $\begin{array}{l}\text { Experimenter places each item on } \\
\text { the table and asks, "Where is the } \\
\text { [item]? Which side?" and points to } \\
\text { left and right. }\end{array}$ & & \\
Tact & "On the right/left" & None \\
& & & \\
\hline
\end{tabular}

Modified Mand Probes. The experimenter placed one item on the table in front of the participant, held up the other item, and asked, "Where do you want me to put the horse/block? Which side?" and pointed to the left and right. This differed from standard mand probes in that the experimenter asked specifically "Which side?" and pointed to both the left and right.

Modified Tact Probes. The experimenter placed both items on the table in front of the participant and asked, "Where is the horse/block? Which side?" and pointed to the left and right. This differed from standard tact probes in that the experimenter asked specifically "Which side?" and pointed to the left and right. 


\section{Results and Discussion}

Figure 1 presents the data for pre-experimental probes and postexperimental probes for each participant. Prior to experimental training, the participants emitted no correct responses during mand or tact probes, with the exception of Participant 4, who scored 1/8 during tact probes. Following tact training, Participants 1 and 2 continued to score 0 correct responses on standard mand probes; however, both participants scored $8 / 8$ correct responses on modified mand probes. Similarly, following mand training, Participants 3 and 4 scored 0 correct responses on standard tact probes. These participants subsequently scored $8 / 8$ and $4 / 8$ on modified tact probes. In summary, the participants demonstrated the emergence of mands or tacts for left/right relations during modified but not standard post-experimental probes.

P1

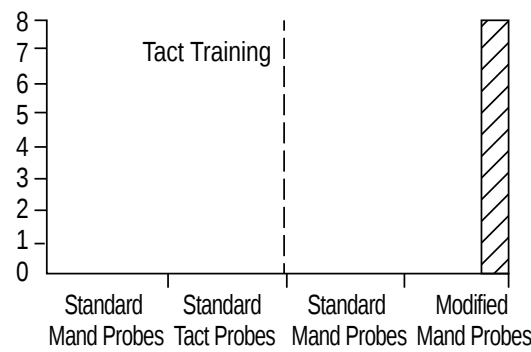

P3

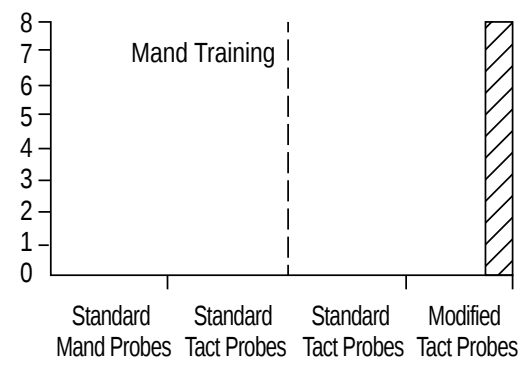

P2

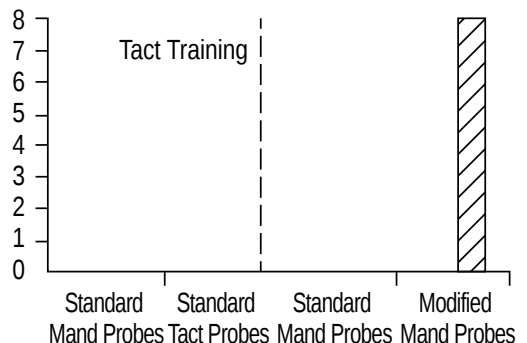

P4

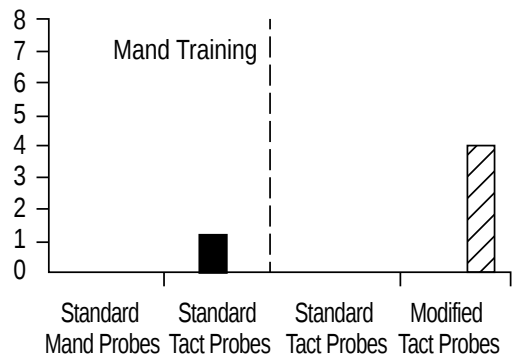

Figure 1. Correct responses for Participants 1 through 4 during pre- and postexperimental probes in Experiment 1.

Although Participant 4 did not achieve criterion, the general findings suggest that no emergence of the untaught operants was observed during standard probe conditions. Nevertheless, all of the participants demonstrated the untaught operant when the antecedent conditions were modified.

The purpose of Experiment 1 was to investigate Lamarre and Holland's (1985) study by using a similar population but incorporating specific discriminative control over emergent responding, which has shown to be effective in previous research examining functional independence (Egan \& Barnes-Holmes, 2009). Results indicated that a lack of appropriate discriminative control, rather than an independence of function between mand and tact operants, more accurately explains these findings.

In Experiment 1, the introduction of the modified antecedent followed testing for the standard antecedent for all four participants. Consequently, 
it is possible that improvement in the untaught operants observed under the modified condition resulted from a simple order effect. Experiment 2 replicated the previous experiment, but counterbalanced the introduction of the modified antecedent condition across participants. In addition, Experiment 2 included the reversed mand/tact training conditions employed by Lamarre and Holland (1985).

\section{Experiment 2}

In Experiment 2, an $A B A B$ reversal design was included to examine the relationship between the modified and standard antecedent conditions and emergent responding. In addition, reversal training, in which left was reinforced as right and right reinforced as left, was employed.

\section{Method}

Participants, Setting, and Materials. The participants were eight normally developing preschool children, aged 4 to 5 years. Each of the four participants from Experiment 1 was included, and four new participants were added. Approximately 4 weeks separated Experiments 1 and 2. Experimental sessions were $25 \mathrm{~min}$ in duration, and each participant was exposed to a maximum of 1 session per day. A plastic cup and a plastic flower were the materials used during all probe and training sessions.

Procedure. The experimental sequence described in Experiment 1 was used in the current experiment, except that postexperimental standard and modified probes were reversed, according to $\mathrm{ABAB}$ reversal design methodology (see Figure 2). In addition, the order of presentation of modified and standard probe conditions was counterbalanced across the four new participants.
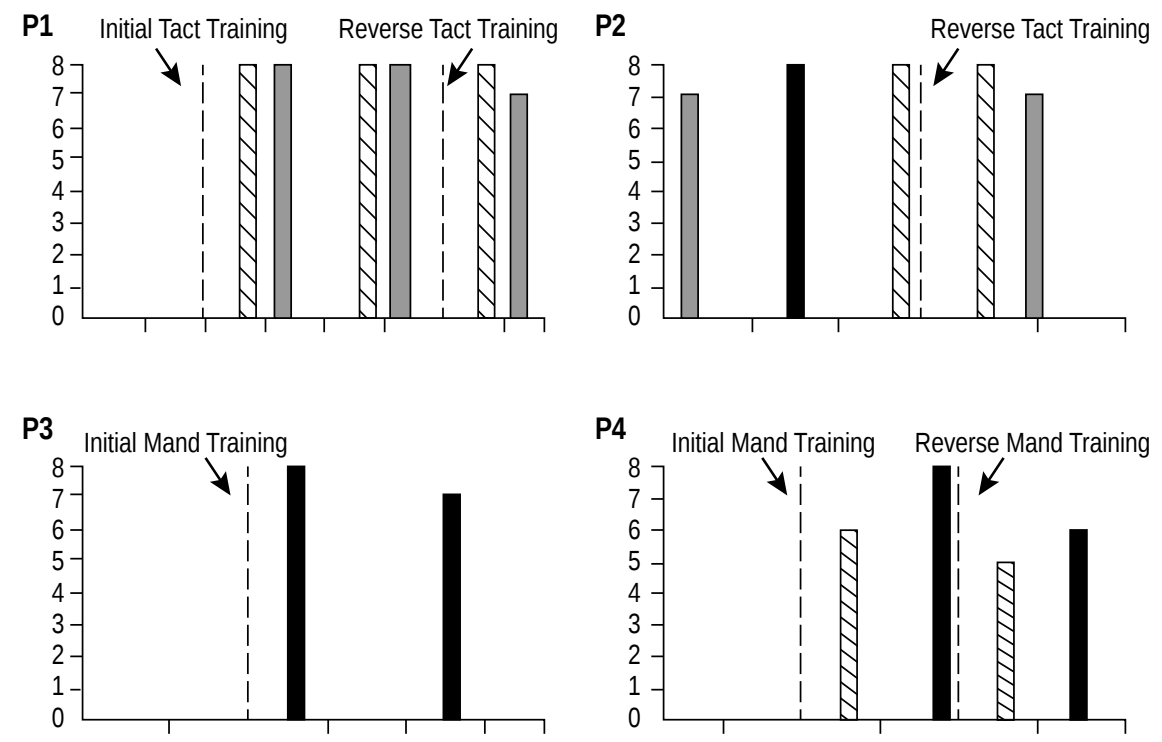

Standard Mand Probes Standard Tact Probes

$\unrhd$ Modified Mand Probes

$\mathbb{M}_{\text {Modified Tact Probes }}$

Figure 2. Experiment 2 training and testing sequence. 
Reverse Mand/Tact Training. Following postexperimental probes, participants were trained to respond to left/right in reverse positions. The reverse mand/tact training was identical to standard mand/tact training procedures; however, the participant was taught to respond to left and right relations in reverse. For example, when a participant manded "on the right," the experimenter placed the object on the left. Training for reversed mands/tacts continued until participants achieved $8 / 8$ consecutive correct responses for each relation.

Postreversal Probes. Following reversal training, two probes were conducted-a mand/tact probe and a listener probe, as described above. Participants who were trained under reversed mand conditions were probed under reversed tact conditions; participants trained under reversed tact conditions were probed under reversed mand conditions.

Upon completion of the study, participants were retrained to respond to initial left/right relations in mand and tact conditions in order to replace the reversed responding acquired during reversal training.

Interobserver Agreement. Interobserver agreement was calculated by dividing the number of agreements by the number of agreements plus disagreements and multiplying by $100 \%$. An agreement was defined as both observers recording an identical classification (either correct or incorrect) for a given trial. Interobserver agreement was collected for 13 of 53 (25\%) probe sessions. Agreement was calculated at 100\%.

\section{Results and Discussion}

Figure 3 presents the data for responses to pre- and postexperimental probes for each participant. Prior to experimental training, the participants scored 0 correct responses during mand and tact probes, with the exception of Participant 2, who scored 7/8 and 8/8 on mand and tact probes, respectively.
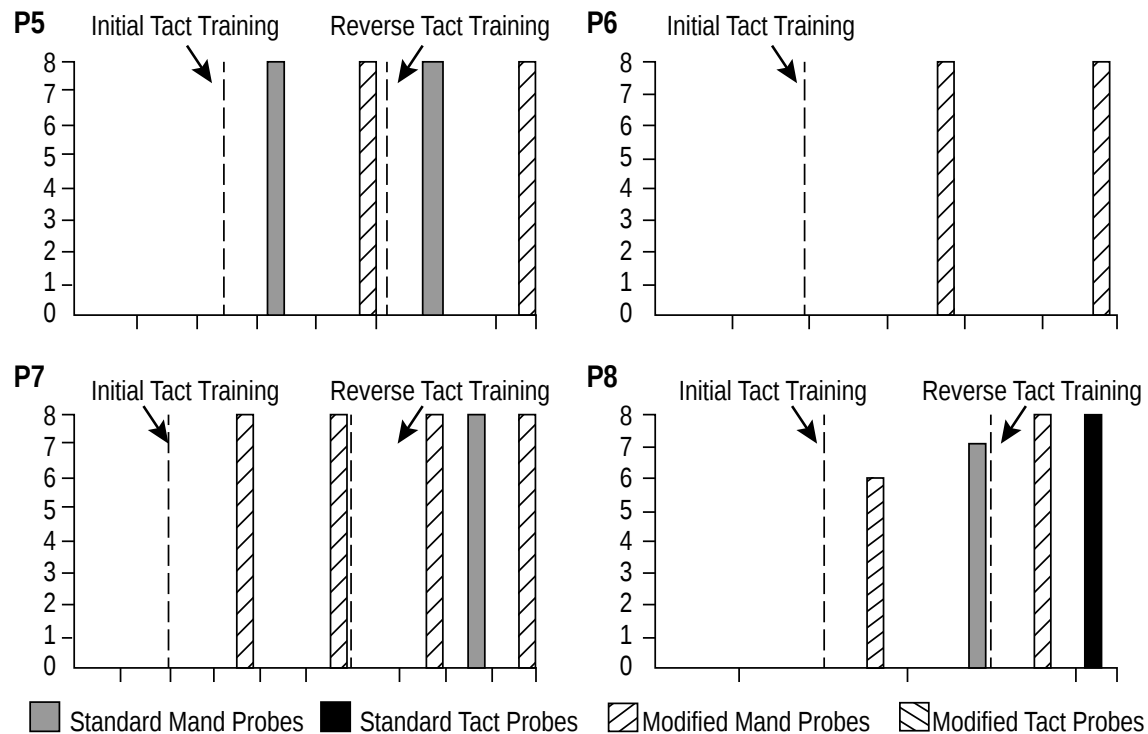

Figure 3. Correct responses for Participants 5 through 12 during pre- and postexperimental probes in Experiment 2. 
Five of the eight participants demonstrated emergent responding for the untaught operant following initial and reverse mand (Participants 4 and 8) or tact (Participants 1, 2, and 5) training in both standard and modified antecedent probe conditions. For Participant 4, however, criterion levels of responding were reached during standard probes following initial mand training only. Thus, these participants demonstrated an emergence of mands or tacts regardless of the antecedent conditions.

Participants 6 and 7 scored $0 / 8$ on standard mand probes and 8/8 during modified mand probes following initial tact training. This pattern was maintained during the next two exposures to standard $(0 / 8)$ and modified $(8 / 8)$ probe conditions. These participants therefore demonstrated that modified antecedent conditions controlled mand emergence. For Participant 7 , the participant scored $0 / 8$ on reverse standard mand probes and $8 / 8$ on reverse modified mand probes following reverse tact training. However, when the participant was re-exposed to these two conditions, 8/8 was produced on both tests. Unfortunately Participant 6 was unavailable for reverse mand training.

Following mand training, Participant 3 scored $8 / 8$ on standard tact probes and $0 / 8$ on modified tact probes. A return to standard tact probe conditions resulted in a score of $7 / 8$, and finally $0 / 8$ on return to modified tact probe conditions. Participant 3 , unlike any other participant in the current study, demonstrated that standard but not modified antecedent conditions controlled tact emergence. Unfortunately, this participant was unavailable for tact reversal training.

In general the participants reliably scored the experimenter's responses as either correct or incorrect during pre and posttraining mand probes. Participants 1 and 7, however, each made one error during probes for reversed mands under standard antecedent conditions following reverse tact training.

In summary, training left/right relations in one verbal operant (either mand or tact) resulted in the emergence of the untaught operant (tact or mand) without direct instruction for five of the eight participants. The remaining three participants demonstrated that emergent responding was present during either modified or standard antecedent conditions, but not both. These results are consistent with those reported in Experiment 1 of the current study. Both experiments have demonstrated that what initially appeared to be functional independence between mands and tacts was more accurately attributed to a lack of appropriate discriminative control.

Participants who received tact training did not appear to demonstrate systematic differences when compared with those who received mand training. Likewise, new participants did not demonstrate consistent differences compared with those who had previously been trained and tested in Experiment 1.

\section{General Discussion}

The current study was designed to investigate the functional independence of mand/tact operants and to evaluate the role of specific $S^{\mathrm{D}} \mathrm{s}$ in demonstrating emergent responding. Experiment 1 partially replicated the experimental procedures of Lamarre and Holland (1985) with a group of normally developing children matched in age to those originally studied. 
Experiment 2 replicated Experiment 1 using the same four participants, and included four new participants. The results initially showed that following mand or tact training, the untrained operant (tact or mand) did not emerge under standard probe conditions. This finding was consistent with the results reported by Lamarre and Holland. However, the use of a modified antecedent in probes for the untrained operant demonstrated that emergent responding was under the control of specific antecedent conditions (P1-4 in Experiment 1, P6 and P7 in Experiment 2).

Three participants (P1, P4, and P8 in Experiment 2) were exposed to modified followed by standard antecedent conditions, and all of these demonstrated immediate emergent responding. This result suggests that the modified antecedent could produce emergence without prior exposure to the standard condition. However, drawing this conclusion requires caution because three of the remaining participants across the two experiments demonstrated immediate emergence when presented with the standard condition first. Perhaps, therefore, P1, P4, and P8 from Experiment 2 would have shown immediate emergence had they been presented with the standard condition first. Future research might investigate this more systematically.

Finally, two participants showed unexpected performances that are worth noting. In Experiment 1, Participant 2 received mand training and failed subsequent standard tact probes. However, in Experiment 2 the participant then scored 8/8 (100\%) correct responses in pre-experimental standard tact probes. In other words, the participant "spontaneously" demonstrated standard tacts, despite the absence of any direct training. Participant 3 received mand training in Experiment 1 and failed subsequent standard tact probes, but passed modified tact probes. In Experiment 2, however, the participant received mand training and passed subsequent standard tact probes, but failed modified tact probes. In other words, the participant demonstrated the expected performance in Experiment 1 but then reversed that performance in Experiment 2. The reason for these unexpected performances remains unknown at the present time. One possible explanation, however, is the involvement of a type of "higher order" stimulus control, in which the participant interpreted the repeated presentation of similar tasks, across experiments, as a type of corrective feedback. In other words, the child responded to the repeated exposure as indicating that the previous performance was incorrect and thus the previous pattern of responding should be reversed. However, this explanation is speculative.

In general, the participants made errors during standard mand or tact probe sessions consisting of responses that likely had well-established histories of reinforcement. For example, the participants emitted responses such as, "On your head," or "Over here" when asked, "Where do you want me to put the [item]?" It seems plausible that participants continued to respond during standard probe sessions with the most recently reinforced responses established outside the experimental conditions. The presentation of the modified antecedent, however, may have functioned as a verbal $S^{D}$ that cued participants to respond to the relevant nonverbal stimuli. This explanation appears consistent with previous research demonstrating that participants' histories of reinforcement for alternative responses influenced the emergence of newly trained mand/tact responses (Egan \& Barnes-Holmes, 2008). 
The present study replicated procedures outlined by Lamarre and Holland (1985) for establishing mand and tact operants. Specific reinforcement was present during mand training; however, no clear method of deprivation was employed to ensure the presence of an establishing operation to evoke the mand response. Thus, it is possible that true mand conditions were not present during mand training and testing. If so, it remains to be determined whether the results reported herein, as well as in the original study by Lamarre and Holland, actually represent cases of functional independence between mands and tacts. It may be the case that the lack of emergent responding reported was a result of ambiguous discriminative control over two operants with separate $S^{\mathrm{D}} \mathrm{s}$, rather than functional independence across mand and tact operants. Future research might test the effect of modified $\mathrm{S}^{\mathrm{D}} \mathrm{s}$ on mand emergence using experimental procedures that clearly contrive an establishing operation for the mand. Furthermore, future studies might examine the role of specific verses generalized consequences in establishing emergent verbal operants.

The current findings have implications for previous research examining functional independence. Two recent studies examining functional independence demonstrated the emergence of mands or tacts immediately following training in the other operant (Petursdottir et al., 2005; Wallace et al., 2006); however, these studies employed different procedural variables during the training and testing conditions. Thus, it is unclear what effect, if any, the $\mathrm{S}^{\mathrm{D}} \mathrm{s}$ had on emergent responding.

Of the studies reporting functional independence between mand and tact operants, most have demonstrated some degree of transfer following specific training procedures (Hall \& Sundberg, 1987; Nuzzolo-Gomez \& Greer, 2004; Sigafoos et al., 1990). These studies demonstrated that once an $\mathrm{S}^{\mathrm{D}}$ was established through training in both operants, functional independence was no longer demonstrated. It seems possible, in light of the current findings, that the initial functional independence observed in previous research was a case of weak discriminative control over emergent responding that was strengthened or clarified by subsequently training a small number of targets. Future studies might further examine the distinction between "functionally independent operants" and "operants with different discriminative stimuli" by testing the effects of a modified antecedent condition during posttraining probes.

These results have implications for the design of verbal behavior programs for instructing basic language. A challenge often faced by behavior analysts working with students with autism spectrum disorders is a lack of emergent responding across verbal operants. Thus, future research on the functional independence of mands and tacts should seek to provide a clear definition of functional independence, and to specify the conditions under which such independence will be observed.

\section{References}

EGAN, C. E., \& BARNES-HOLMES, D. (2009). Emergence of tacts following mand training in young children with autism. Journal of Applied Behavior Analysis, 42, 691-696.

HALL, G., \& SUNDBERG, M. L. (1987). Teaching mands by manipulating conditioned establishing operations. The Analysis of Verbal Behavior, 5, 41-53. 
LAMARRRE, J., \& HOLLAND, J. (1985). The functional independence of mands and tacts. Journal of the Experimental Analysis of Behavior, 43, 5-19.

MURPHY, C., \& BARNES-HOLMES, D. (2009). Establishing derived manding for specific amounts with three children: An attempt at synthesizing Skinner's Verbal Behavior with relational frame theory. The Psychological Record, 59, 75-91.

NUZZOLO-GOMEZ, R., \& GREER, R. D. (2004). Emergence of untaught mands or tacts of novel adjective-object pairs as a function of instructional history. The Analysis of Verbal Behavior, 20, 63-76.

PARTINGTON, J.W., SUNDBERG, M.L., NEWHOUSE, L., \& SPENGLER, S.M. (1994). Overcoming an autistic child's failure to acquire a tact repertoire. Journal of Applied Behavior Analysis, 27, 733-734.

PETURSDOTTIR, A. I., CARR, J. E., \& MICHAEL, J. ( 2005). Emergence of mands and tacts of novel objects among preschool children. The Analysis of Verbal Behavior, 21, 59-74.

SCHLINGER, H. (2008). The long good-bye: Why B. F. Skinner's Verbal Behavior is alive and well on the 50th anniversary of its publication. The Psychological Record, 58, 329-337.

SIGAFOOS, J., REICHLE, J., DOSS, S., HALL, K., \& PETTITT, L. (1990). "Spontaneous" transfer of stimulus control from tact to mand contingencies. Research in Developmental Disabilities, 11, 165-176.

SKINNER, B. F. (1957). Verbal behavior. New York: Appleton-Century-Crofts.

SUNDBERG, M. L., \& MICHAEL, J. (2001). The value of Skinner's analysis of verbal behavior for teaching children with autism. Behavior Modification, $25,698-724$.

SUNDBERG, M. L., SAN JUAN, B., DAWDY, M., \& ARGUELLES, M. (1990). The acquisition of tacts, mands, and intraverbals by individuals with traumatic brain injury. The Analysis of Verbal Behavior, 8, 83-99.

TWYMAN, J. (1996). The functional independence of impure mands and tacts of abstract stimulus properties. The Analysis of Verbal Behavior, 13, 1-19.

WALLACE, M. D., IWATA, B. I., \& HANLEY, G. P. (2006). Establishment of mands following tact training as a function of reinforcer strength. Journal of Applied Behavior Analysis, 39, 17-24. 